\title{
Determinants and Effects of User Delight with Theme Park Apps
}

\author{
Ting Long \\ University of Turku \\ ting.long@utu.fi
}

\author{
Reima Suomi \\ University of Turku \\ reima.suomi@utu.fi
}

\begin{abstract}
The rise of mobile apps intended to enhance the customer experience has prompted theme park operators to implement theme park apps with which to improve their relationships with visitors. The value of user delight in theme park apps has attracted considerable attention. To develop a delightful theme park app, however, theme park operators require a more detailed understanding of how they can optimize the impacts of theme park apps. By conducting an empirical study of 204 users of theme park apps through an online survey, this study found that delight has substantial impacts on users' continuance intention, recommendation, offering feedback, and revisit intention regarding theme parks. Additionally, delight is determined by entertainment, aesthetic design, and achievement-related gamification. This study contributes to the literature on delight in the context of theme park apps and offers practical implications for theme park app designers and operators.
\end{abstract}

\section{Introduction}

Mobile applications (apps) designed explicitly for theme parks have become popular in recent years. Particularly in response to the challenges of supporting social distancing in place during the COVID-19 pandemic, some theme parks have implemented theme park apps to improve safety and visitors' experiences, as well as aiding in reopening and recovery. These theme park apps enable theme park operators to offer visitors a seamless experience throughout the entire journey, including before, during, and after their visit $[1,2]$. For instance, by using a theme park app, a visitor can book digital tickets via online booking services before the visit, avoid long lines via virtual queues during the visit, and offer their feedback directly after the visit. However, like other mobile apps, theme park apps are also facing tough competition from similar products [3]. To obtain a competitive advantage, many app designers and operators attempt to delight users by offering rich features with which to attract and retain users [3].

Delight refers to a profoundly positive emotion generated via an individual's expectations being exceeded to a surprise degree [4, 5]. Unlike user satisfaction, which is mainly generated by fulfilling expectations, user delight is largely derived from unexpected and surprising positive service experiences $[4,5]$. While users expect a certain level of functionality, some features may exceed their initial expectations [3]. For instance, a theme park app user may discover unexpected features that may delight them, such as real-time virtual queues that enable them to avoid long physical lines. These delighted users may be more likely to keep this app on their smartphones and revisit the theme park. Though delighting users is promising in terms of exhibiting positive outcomes, few studies have examined the role of delight in the context of theme park apps. As essential channels for theme park operators to use in improving relationships with visitors, mobile apps are expected to not only meet visitors' basic expectations but also delight and surprise them. Therefore, it is important to examine delight in the context of theme park apps.

The prior literature on marketing and service has emphasized the significance of delight in improving customer loyalty and word of mouth, and some studies have reported that merely satisfying customers does not necessarily lead to these positive outcomes [6-8]. Companies are suggested to delight customers to develop long-term relationships with them [5, 9]. However, little research has examined the importance of delight in IS service. IS service providers can also enhance their relationships with users by exceeding users' expectations through innovative and unforeseen design. In the studied context, a delighted user of a theme park app might not only continue their use of the app but also intend to perform citizenship behaviors, such as recommend it to others and offer feedback to designers directly. Thus, there is clear value in investigating whether such delight can predict users' continuance intention, recommendation, and feedback behaviors in the context of theme park apps. 
Moreover, our understanding of the antecedents of user delight remains fragmented. Prior research has suggested that surprise and joy are two essential drivers of delight regarding an IS [6, 9]. However, these studies have mainly examined the antecedents of delight from the emotional perspective and largely ignored the influence of users' cognitive assessments, such as users' assessments regarding the design of a theme park app [3, 7]. Vivid visual design, entertainment elements, and gamification techniques may delight users. However, little research has examined which designs/features can induce user delight in theme park apps. Therefore, it is vital to investigate the antecedents of delight from the cognitive perspective in the context of theme parks.

Furthermore, in the context of mobile apps related to tourism, past studies have mainly centered on general travel apps (such as TripAdvisor) $[10,11]$ and social media apps (such as Facebook and Instagram) $[12,13]$, whereas little research has examined mobile apps designed explicitly for theme parks. The use of theme park apps may be different from these other cases. A theme park app is intentionally designed for a theme park, and it is an all-in-one app intended to eliminate pain points for visitors, such as long queueing times and getting lost. Additionally, theme parks allow visitors to experience the bodily sensations associated with immersion in the environment [14]. Unlike conventional destinations, theme parks offer visitors an unusual world in which they can escape from their daily lives [15]. As such, the visiting experiences in theme parks may affect visitors' use of theme park apps. Hence, a finergrained investigation of the mobile app use in the particular context of theme parks is important to understand the differences and common patterns of individual use of mobile apps in different travel contexts.

In light of the practical phenomena and theoretical gap, this research seeks to examine the determinants and effects of delight in the context of theme park apps. To achieve this objective, we propose that gamification techniques (including social-related gamification and achievement-related gamification), aesthetic design, and entertainment design are key antecedents of delight from a cognitive perspective. In addition, based on prior studies, we posit that delight leads to four behavioral outcomes: continuance intention, recommendation, feedback, and revisit intention. The proposed research model has been tested with empirical data gathered via an online survey with 204 theme park app users in China.

The remainder of this article is organized as follows: first, we review the related literature on theme park apps and user delight. Next, after presenting the proposed research model and hypotheses, we introduce the research method used to collect and analyze the data. Then, we summarize the research finding with a discussion. Finally, we address the theoretical contributions and practical implications, followed by the limitations and future research directions.

\section{Literature review}

\subsection{Use of theme park apps}

With the rapid development of mobile apps, the theme park industry has considered mobile apps to be a form of advertising and a marketing channel to use in securing a competitive position. Many theme park brands, such as LEGOLAND and Disney Parks, have focused on establishing an app to improve visitors' experiences, reduce friction, and maximize fun. According to the Omnico report, $95 \%$ of global theme park visitors would like to spend money with the right app [16]. The right app for a theme park should include functions or features that can be used to eliminate friction points (such as long queues), as well as to allow altering upcoming events and promotions, planning day routes, and touchless payment [16].

In the prior literature on tourism and hospitality, there are two main research streams regarding mobile apps. One research stream focuses on the motivations for using mobile apps while traveling. For instance, Tussyadiah [17] found that mobile apps can be utilized for various purposes, such as information searching, navigation, and information sharing. In [15], it was found that the reasons for using mobile apps while traveling can be classified into three types: utilitarian (such as navigation), hedonic (such as listening to music), and relational (such as social networking).

The other research stream emphasizes the impacts of using mobile apps on users' behaviors. For instance, the findings of Wang et al. [18] indicate that the usage of mobile apps could affect users' behaviors in the pre-, during-, and after-travel stages. Specifically, visitors can plan less before traveling because related information will be readily accessible with a mobile app and they can also book a ticket or hotel via the app [18]. During the trip, visitors are equipped to efficiently manage their on-site trip as planned and respond to unexpected situations during traveling [18, 19]. After the trip, visitors can store their memories, share their experiences, and offer feedback [20].

However, thus far, little attention has been paid to theme park apps. Unlike general travel apps (e.g., TripAdvisor), a theme park app is intentionally designed for and operated by a theme park. Such an app can be used not only to enhance visitors' on-site 
experiences but also to promote the brand of a theme park (e.g., offering loyalty points). Questions regarding how users react to a theme park app and whether app use leads to improved behavioral intentions remain unanswered. Recent research has emphasized the significance of the need to delight customers because many of those who are merely satisfied discontinue using certain apps and switch to similar products $[5,8]$. Thus, this study seeks to examine the role of delight in the context of theme park apps.

\subsection{User delight}

There are two research perspectives on the conceptualization of customer delight in the marketing and service literature [9]. One assumes that customer delight reveals an extremely high level of satisfaction, referred to as the "zone of delight" [21]. The other presumes that delight is a distinct affective customer response that involves positive emotions such as surprise, excitement, and joy [5, 9]. By comparing these two research perspectives, research by Finn [9] has supported the second assumption and suggested that customer delight is a different service performance metric that must be observed and managed separately from satisfaction. Delight and satisfaction exert separate influences on customer behaviors [9]. For instance, Bartl et al. [6] found that delight has stronger effects on purchase intentions than satisfaction does in online contexts. Likewise, in the context of mobile apps, delight has stronger impacts on user citizenship behaviors than satisfaction does, while satisfaction has a greater influence on continuance intention [3]. Barnes et al. [8] pointed out that delighted users perform better on measures of loyalty, commitment, and willingness to pay. Based on these earlier research findings, this study prefers the conceptualization of user delight as an emotional response during a service experience within a theme park app.

In addition, some studies have investigated the antecedents of delight from various perspectives. Delight appears when customers receive a positive surprise beyond their expectations [22]. The surprise and unexpected experiences trigger arousal, which induces pleasure, ultimately creating delight [4]. From the emotional perspective, joy and surprise have been the antecedents of delight examined most frequently in the prior marketing and service literature [7]. Customers' cognitive evaluations, such as unexpectedness and confirmation, have been found to affect delight in the context of mobile apps [3]. Similarly, usefulness and entertainment have also been found to be essential antecedents of delight in the context of corporate websites [6]. In a qualitative study, Esnaashari and Rehm [23] found that students could be delighted by gamification in the context of an educational technology tool.

To sum up, these research findings on delight indicate that the existing literature may not be able to explain the role of delight in the context of theme park apps effectively. Though the prior marketing and service literature has posited that delight can affect customers' behaviors and be influenced by external factors, few studies have investigated what causes user delight and what outcomes user delight can produce in the context of theme park apps. Therefore, there is value for additional research intended to provide an enhanced understanding of the antecedents and consequences of delight in the context of theme park apps.

\section{Research model and hypotheses}

\subsection{The proposed model}

To better understand the role of user delight in the context of theme park apps, in this study, we propose a conceptual model based on prior studies. The model assumes that delight has positive influences on users' behavioral intentions, including continuance intention, recommendation, offering feedback toward the app, and revisit intention regarding theme parks. In addition, delight is hypothesized to be affected by social-related gamification, achievement-related gamification, aesthetic design, and entertainment. Furthermore, the age, gender, income level, length of visiting time, and types of residence are considered as moderators. Figure 1 illustrates the proposed research model.

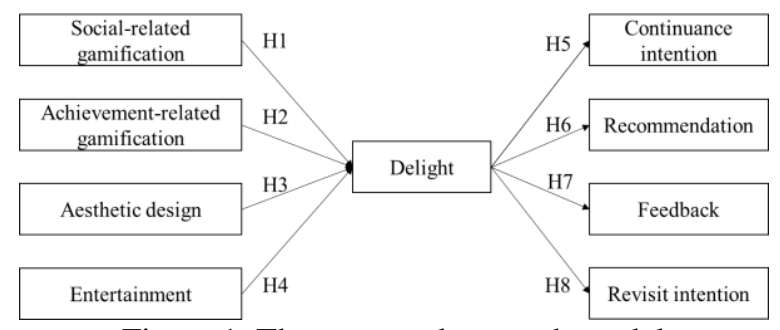

Figure 1. The proposed research model

\subsection{Hypotheses}

Gamification refers to designing an IS by including game-design elements and principles, with the additional goal of influencing users' behaviors [24]. Prior studies have suggested that some gamification features lead to emotional outcomes, such as enjoyment and fun [25]. In [24], gamification features are classified into three types, including 
immersion-related features (such as customization or personalization), achievement-related features (such as points, scores, or experience points), and socialrelated features (such as social networking). These three types of gamification have different influences on users' intrinsic need satisfaction [24]. Achievement- and social-related gamification affect the satisfaction of competence, autonomy, and relatedness needs, whereas immersion-related gamification only predicts the satisfaction of autonomy needs [24]. In the context of theme park apps, some operators have implemented achievementrelated features (such as brand points) and socialrelated features (such as visit cooperation) to improve user experience [26]. As such, these two types of gamification also hold value in terms of delighting users. For instance, users may be delighted if they find that gamification design exceeds their initial expectations regarding achievements and social networks. Thus, we develop the following hypotheses:

H1: Social-related gamification positively affects users' delight with a theme park app.

H2: Achievement-related gamification positively affects users' delight with a theme park app.

The interface design is important for a mobile app because the sensory experience of using an app can also affect users' behavioral intentions [27]. Visual design defines the balance and aesthetic of mobile apps via colors, images, shapes, or animations [27]. An aesthetically pleasing and attractive interface not only makes an app easy to use but also creates an emotional connection with users [28]. Visual cues such as animations enable designers to alter the appearance of an app in a unique and vivid way and have the potential to directly influence user delight. For instance, an interesting animation can help keep users entertained and delighted while the app is processing. Prior studies have shown a relationship between aesthetic design and users' emotional states. For instance, Hsieh et al. [28] found that the aesthetic design of a branded app (e.g., Starbucks) has positive influences on the establishment of enjoyment and pleasure. Hence, it is reasonable to assume that aesthetic design of a theme park app can help users feel delighted. Therefore, we propose the following hypothesis:

H3: Aesthetic design positively affects users' delight with a theme park app.

Entertainment refers to a reflection of the hedonic aspects of using an IS [28, 29]. The entertainment provided by a theme park app may include music, videos, and pictures regarding the theme park [30]. Once users experience entertainment when using an app, their attitude and behavioral intentions toward it will be significantly influenced. Prior studies have found that entertainment can lead to positive customer emotions. For instance, Hsieh et al. [28] found that entertainment is positively related to users' perceived pleasure. Similarly, an entertaining app with rich features may exceed users' expectations and eventually evoke delight. Therefore, we suggest the following hypothesis:

H4: Entertainment positively affects users' delight with a theme park app.

Continuance intention refers to users' intention to maintain their use of an IS [31]. Some theme park app users might visit a theme park only once and discontinue their app use after completing their theme park visit, even though they are satisfied with the apps. Hence, mere satisfaction may not fully explain continuance intention regarding a theme park app. According to the prior literature, delighting users tend to higher levels of behavioral outcomes such as continuance intention, loyalty, and repurchase intention $[3,6,8,32]$. Delighted users may perceive a higher risk associated with discontinuance or switching than merely satisfied users because discontinuance and switching will create a more significant loss for delighted users [33]. We follow this research stream and propose that delight has a positive impact on continuance intention. Thus, the following hypothesis is suggested:

H5: Users' delight with a theme park app positively affects their intention to continue using it.

In addition to continuance intention, delight may also affect users' citizenship behaviors. Prior studies have pointed out that delight is a crucial determinant of customer citizenship behaviors [3, 34]. For instance, Berman [22] found that delighted users are willing to share positive words with others. In work by Hsu et al. [3], delight exerts a stronger influence on citizenship behaviors than satisfaction, including word-of-mouth and offering feedback. Hence, it is reasonable to assume that delighted users of a theme park app are more likely to perform citizenship behaviors, such as recommend the theme park apps to others or offer feedback to app designers. Therefore, the following hypotheses are proposed:

H6: Users' delight with a theme park app positively affects their recommendation.

H7: Users' delight with a theme park app positively affects their feedback.

Prior studies have indicated that delight affects customers' repurchase intention [6, 9, 22]. Likewise, a delightful experience with using a theme park app may also affect users' intention to revisit the theme park. Thus, we suggest the following hypothesis:

H8: Users' delight with a theme park app positively affects their intention to revisit the theme park. 
Finally, considering the potential effects of user features such as age, gender, income level, residence type, and length of visiting time as moderators has been suggested for those investigating customer delight and mobile travel app use [4, 9, 28, 35]. Thus, we hypothesize that these factors moderate the proposed relationships in our research model.

\section{Research method}

\subsection{Development of the measurement}

We adapted previously validated instruments to measure the constructs included in the proposed research model. A seven-point Likert scale ranging from " 1 = strongly disagree" to " 7 = strongly agree" was used to measure all items. Specifically, the measurement items for aesthetic design came from $[36,37]$. The source items for delight were informed by [5]. The measurement items for social-related gamification and achievement-related gamification were taken from [24]. Entertainment was measured with items from [38] and [39]. The items for continuance intention were adopted from [31]. Recommendation was measured with the measurement items adopted from [32]. Feedback was measured with items from [3]. The items for revisit intention came from [40]. The details are presented in the Appendix.

\subsection{Data collection}

We collected the data via an online survey in China. We initiated the survey questionnaire in English because we adapted all constructs from previously validated scales taken from international journals. Then, the first author, who is fluent in both Chinese and English, translated the questionnaire into Chinese. Next, we conducted a pilot study to gather feedback and validate the quality of the translation. Finally, we finalized the questionnaire and sent it to our target respondents via the sample service of wjx.com.

The survey questionnaire includes three parts. First, we introduced the research purpose, assured participants of the confidentiality of data, gathered contact information, and informed consent. Only those who agreed to participate and reported having used theme park apps proceeded to complete the questionnaire. Then, we asked the respondents about their demographic information and prior experience with visiting theme parks. Finally, we required respondents to report their perceptions regarding the use of theme park apps.
We received 224 answers. After eliminating the answers with invalid data, a total of 204 valid responses were used for data analysis. As shown in Table 1, the majority of respondents were aged between 18 and 35 (67.6\%), 31.9\% were men, and $68.1 \%$ were women.

Table 1. Descriptive statistics of respondents' characteristics

\begin{tabular}{|l|l|c|c|}
\hline Measure & Items & $\begin{array}{l}\text { Freque } \\
\text { ncy }\end{array}$ & $\begin{array}{l}\text { Percent } \\
(\%)\end{array}$ \\
\hline \multirow{4}{*}{ Age } & $>18$ and $\leq 25$ & 34 & 16.7 \\
\cline { 2 - 4 } & $>26$ and $\leq 35$ & 138 & 67.6 \\
\cline { 2 - 4 } & $>36$ and $\leq 45$ & 29 & 14.2 \\
\cline { 2 - 4 } & $>46$ and $\leq 55$ & 1 & 0.5 \\
\cline { 2 - 4 } & $>55$ & 2 & 1.0 \\
\hline \multirow{4}{*}{ Gender } & Male & 65 & 31.9 \\
\cline { 2 - 4 } level & Female & 139 & 68.1 \\
\cline { 2 - 4 } & $15,001-25,000$ RMB & 21 & 8.8 \\
\cline { 2 - 4 } & $25,001-35,000$ RMB & 21 & 10.3 \\
\cline { 2 - 4 } & $35,001-45,000$ RMB & 15 & 7.4 \\
\cline { 2 - 4 } & $45,001-55,000$ RMB & 19 & 9.3 \\
\cline { 2 - 4 } & $\geq 55,000$ RMB & 110 & 53.9 \\
\hline \multirow{4}{*}{$\begin{array}{l}\text { Residenc } \\
\text { e type }\end{array}$} & Local & 128 & 62.7 \\
\cline { 2 - 4 } $\begin{array}{l}\text { Length } \\
\text { of }\end{array}$ & Non-local & 76 & 37.3 \\
\cline { 2 - 4 } $\begin{array}{l}\text { visiting } \\
\text { time }\end{array}$ & Half-day and less & 4 & 2.0 \\
\cline { 2 - 4 } & One to two days & 78 & 34.9 \\
\cline { 2 - 4 } & Over two days & 10 & 4.9 \\
\hline
\end{tabular}

\subsection{Common method bias and collinearity}

We used Harman's single-factor test to evaluate common method bias. The result showed that the highest total variance for any factor was $34.5 \%$, lower than the recommended maximum of $50 \%$, thereby suggesting that common method bias was not a critical issue in this research [41]. We also employed the variance inflation factors (VIFs) recommended by Kock and Lynn [42] to test collinearity. The results showed that all VIF values ranged from 1.272 to 2.761 , lower than 3.3 , indicating collinearity was also not a critical concern in this research [42].

\subsection{Data analysis}

We tested the measurement model and structure model by using SmartPLS 3.0. To validate the reliability and convergent validity, we assessed the factor loadings for each item, composite reliability (CR), Cronbach's alpha, and average variance extracted (AVE). We deleted one item, CI3, due to its low factor loading. The results in Table 2 show that factor loadings, Cronbach's alpha, and CR values were 
greater than 0.7 and that AVE exceeded 0.5, indicating adequate reliability and convergent validity.

To assess discriminant validity, we used both the Fornell-Larcker criterion [43] and the heterotraitmonotrait (HTMT) ratio of correlation [44]. As presented in Table 3, each construct's correlations with the other constructs were all below the square root of the construct's AVE [43]. Moreover, in Table 4, all values of HTMT were smaller than the recommended upper limit of 0.90 [44]. Therefore, discriminant validity was established in this study.

Table 2 . The results for test reliability and convergent validity

\begin{tabular}{|c|c|c|c|c|c|}
\hline $\begin{array}{l}\text { Construc } \\
\text { t }\end{array}$ & Items & \begin{tabular}{|l|} 
Factor \\
loading
\end{tabular} & $\begin{array}{l}\text { Cronbac } \\
\text { h's } \\
\text { alpha }\end{array}$ & CR & AVE \\
\hline \multirow[t]{5}{*}{$\mathrm{AE}$} & AE1 & 0.802 & \multirow[t]{5}{*}{0.826} & \multirow[t]{5}{*}{0.878} & \multirow[t]{5}{*}{0.589} \\
\hline & AE2 & 0.729 & & & \\
\hline & $\mathrm{AE} 3$ & 0.762 & & & \\
\hline & $\mathrm{AE} 4$ & 0.749 & & & \\
\hline & AE5 & 0.795 & & & \\
\hline \multirow[t]{3}{*}{$\overline{\mathrm{DE}}$} & DE1 & 0.840 & \multirow[t]{3}{*}{\begin{tabular}{|l|l|}
0.818 \\
\end{tabular}} & \multirow[t]{3}{*}{0.892} & \multirow[t]{3}{*}{0.734} \\
\hline & DE2 & 0.869 & & & \\
\hline & DE3 & 0.860 & & & \\
\hline \multirow[t]{4}{*}{ SG } & SG1 & 0.817 & \multirow[t]{4}{*}{0.852} & \multirow[t]{4}{*}{0.900} & \multirow[t]{4}{*}{0.693} \\
\hline & SG2 & 0.799 & & & \\
\hline & SG3 & 0.862 & & & \\
\hline & SG4 & 0.851 & & & \\
\hline \multirow[t]{4}{*}{ AG } & AG1 & 0.749 & \multirow[t]{4}{*}{0.859} & \multirow[t]{4}{*}{0.905} & \multirow[t]{4}{*}{\begin{tabular}{|l|l|} 
\\
\end{tabular}} \\
\hline & AG2 & 0.859 & & & \\
\hline & AG3 & 0.867 & & & \\
\hline & AG4 & 0.876 & & & \\
\hline \multirow[t]{4}{*}{ EN } & EN1 & 0.745 & \multirow[t]{4}{*}{0.778} & \multirow[t]{4}{*}{0.858} & \multirow[t]{4}{*}{0.601} \\
\hline & EN2 & 0.810 & & & \\
\hline & EN3 & 0.813 & & & \\
\hline & EN4 & 0.732 & & & \\
\hline \multirow[t]{3}{*}{ REI } & REI1 & 0.857 & \multirow[t]{3}{*}{0.814} & \multirow[t]{3}{*}{0.890} & \multirow[t]{3}{*}{0.729} \\
\hline & REI2 & 0.836 & & & \\
\hline & REI3 & 0.868 & & & \\
\hline \multirow[t]{3}{*}{ CI } & CI1 & 0.760 & \multirow[t]{3}{*}{0.724} & \multirow[t]{3}{*}{0.844} & \multirow[t]{3}{*}{0.644} \\
\hline & CI2 & 0.806 & & & \\
\hline & CI4 & 0.839 & & & \\
\hline \multirow[t]{4}{*}{ FE } & FE1 & 0.751 & 0.807 & 0.873 & 0.633 \\
\hline & FE2 & 0.782 & & & \\
\hline & FE3 & 0.825 & & & \\
\hline & FE4 & 0.823 & & & \\
\hline REC & REC1 & 0.728 & 0.716 & 0.841 & 0.640 \\
\hline & REC2 & 0.816 & & & \\
\hline & REC3 & 0.850 & & & \\
\hline
\end{tabular}

(Notes: AE: Aesthetic design; DE: Delight; SG:

Social-related gamification; AG: Achievement-related gamification; EN: Entertainment; REI: Revisit intention; CI: Continuance intention; FE: Feedback; REC: Recommendation; CR: Composite reliability; AVE: Average variance extracted)
Table 3. Discriminant validity: Fornell-Larcker criterion

\begin{tabular}{|l|l|l|l|l|l|l|l|l|l|}
\hline & AE & DE & SG & AG & EN & REI & CI & FE & REC \\
\hline AE & 0.768 & & & & & & & & \\
\hline DE & 0.565 & 0.857 & & & & & & & \\
\hline SG & 0.522 & 0.523 & 0.839 & & & & & & \\
\hline AG & 0.430 & 0.457 & 0.669 & 0.832 & & & & & \\
\hline EN & 0.641 & 0.599 & 0.536 & 0.459 & 0.775 & & & & \\
\hline REI & 0.416 & 0.325 & 0.332 & 0.300 & 0.387 & 0.854 & & & \\
\hline CI & 0.589 & 0.375 & 0.291 & 0.229 & 0.574 & 0.448 & 0.802 & & \\
\hline FE & 0.529 & 0.416 & 0.432 & 0.409 & 0.492 & 0.364 & 0.461 & 0.796 & \\
\hline REC & 0.509 & 0.403 & 0.398 & 0.404 & 0.502 & 0.423 & 0.645 & 0.564 & 0.800 \\
\hline
\end{tabular}

Table 4. Discriminant validity: Heterotrsaitmonotrait (HTMT)

\begin{tabular}{|l|l|l|l|l|l|l|l|l|l|}
\hline & AE & DE & SG & AG & EN & REI & CI & FE & REC \\
\hline AE & & & & & & & & & \\
\hline DE & 0.677 & & & & & & & & \\
\hline SG & 0.616 & 0.625 & & & & & & & \\
\hline AG & 0.511 & 0.545 & 0.781 & & & & & & \\
\hline EN & 0.793 & 0.749 & 0.655 & 0.562 & & & & & \\
\hline REI & 0.502 & 0.397 & 0.392 & 0.356 & 0.486 & & & & \\
\hline CI & 0.761 & 0.482 & 0.364 & 0.283 & 0.762 & 0.577 & & & \\
\hline FE & 0.645 & 0.509 & 0.521 & 0.496 & 0.619 & 0.444 & 0.591 & & \\
\hline REC & 0.654 & 0.525 & 0.511 & 0.522 & 0.672 & 0.554 & 0.880 & 0.740 & \\
\hline
\end{tabular}

We tested the structural model by using the bootstrapping technique in SmartPLS, including the path significance and variance explained. As shown in Figure 2, the research model explains $45.3 \%$ of variance for delight, $14.3 \%$ of variance for continuance intention, $17.3 \%$ of variance for recommendation, $16.2 \%$ of variance for feedback, and $10.6 \%$ of variance for revisit intention. Achievementrelated gamification $(\beta=0.164, p<0.05)$, aesthetic design $(\beta=0.234, p<0.01)$, and entertainment $(\beta=$ $0.313, \mathrm{p}<0.001$ ) have significantly positive impacts on delight. Delight positively affects continuance intention $(\beta=0.375, \mathrm{p}<0.001)$, recommendation $(\beta=$ $0.416, p<0.001)$, feedback $(\beta=0.403, p<0.001)$, and revisit intention $(\beta=0.325, \mathrm{p}<0.001)$. There is no significant association between social-related gamification and delight. Therefore, H2, H3, H4, H5, $\mathrm{H} 6, \mathrm{H} 7$, and $\mathrm{H} 8$ are supported, while $\mathrm{H} 1$ is not.

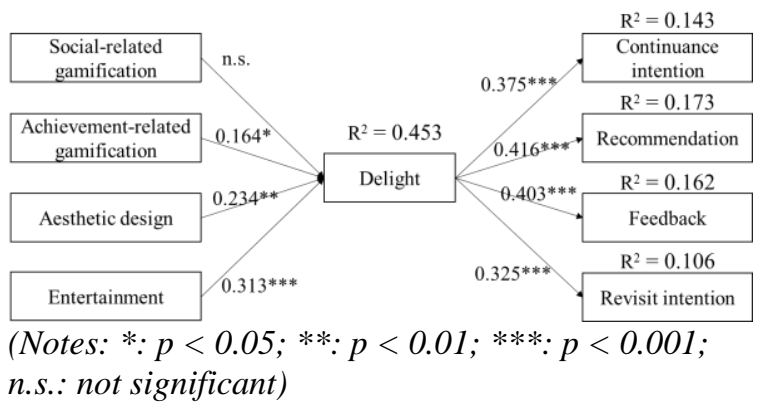

Figure 2. Results of the structural model 


\subsection{Post-hoc analysis}

To ascertain whether delight mediates the relationships between its antecedents and consequences, we elucidated the mediation effect by following the guidelines proposed by Nitzl et al. [45]. The results showed that there is no mediation effect on the part of delight in this study.

To examine whether there are differences between different user groups, we conducted a multigroup analysis (MGA) to test the moderation effect of age, gender, residence type, income level, and length of visiting. We classified respondents into two age groups: Age Group 1 includes those aged 18-35, and Age Group 2 includes those aged above 35. Two groups based on income level were also used: a high income level was associated with an annual income above 55,000 RMB, and a low income level was associated with an annual income below 55,000 RMB.

Prior to MGA, we tested measurement invariance by using the measurement invariance of composite models (MICOM) proposed by Henseler et al. [46]. The results showed that partial measurement invariance was established regarding age, residence type, and length of visiting. Full measurement invariance was verified regarding income level and gender. Thus, performing MGA was acceptable in this study [46].

We found that there were no significant differences regarding age, income level, gender, and length of visiting. As shown in Table 5, a significant difference existed between local and non-local users regarding the path from entertainment to delight.

Table 5. Results of testing residence type as a moderator

\begin{tabular}{|l|l|l|l|}
\hline & \multicolumn{2}{|l|}{$\begin{array}{l}\text { Comparison by } \\
\text { residence type }\end{array}$} & \multicolumn{2}{|l|}{$\begin{array}{l}\text { Path coefficients of } \\
\text { separate structural models }\end{array}$} \\
\cline { 2 - 4 } & $\begin{array}{l}\text { Local vs. non- } \\
\text { local }\end{array}$ & $\begin{array}{l}\text { Local } \\
(\mathrm{N}=128)\end{array}$ & $\begin{array}{l}\text { Non-local } \\
(\mathrm{N}=76)\end{array}$ \\
\hline H1 & n.s. & n.s. & n.s. \\
\hline H2 & n.s. & $0.226^{* *}$ & n.s. \\
\hline H3 & n.s. & n.s. & $0.284^{* *}$ \\
\hline H4 & p <0.05 & $0.216^{* *}$ & $0.482^{* * *}$ \\
\hline H5 & n.s. & $0.347^{* * *}$ & $0.454^{* * *}$ \\
\hline H6 & n.s. & $0.407^{* * *}$ & $0.416^{* *}$ \\
\hline H7 & n.s. & $0.404^{* * *}$ & $0.443^{* * *}$ \\
\hline H8 & n.s. & $0.239^{* *}$ & $0.434^{* * *}$ \\
\hline
\end{tabular}

(Notes: $* *: p<0.01 ; * * *: p<0.001 ;$ n.s.: not

significant)

\section{Discussion}

Our study has generated several interesting findings. First, social-related gamification has not been found to be an antecedent of delight in theme park apps. This is not consistent with prior findings on the effects of social-related gamification on satisfaction [24]. One potential explanation is that users typically share their experiences with others or develop visit-cooperation via other social media platforms (such as Facebook or Instagram) rather than a theme park app. Thus, social-related gamification may not be enough to evoke user delight, even though users are satisfied with such features.

Second, achievement-related gamification is an important determinant of delight in theme park apps. This is in line with prior findings on the positive influences of such gamification on users' affective attitudes [24]. This indicates that theme park app designers should include certain achievement-related features, such as tasks or theme park points, to delight users. When users use theme park apps, they can have a delightful experience through interacting with these achievement-related functions.

Third, we found that aesthetic design has a positive effect on delight. This is consistent with prior findings on the role of visual attractiveness in evoking positive emotions, such as pleasure and enjoyment [3, 27]. Our findings suggest that it is important to emphasize the role of aesthetic design in inducing delight. A visually attractive and vivid interface of a theme park app can create a delightful experience for users.

Fourth, entertainment has been found to be an important antecedent of delight in theme park apps. This is consistent with prior findings. For instance, Bartl et al. [6] found that entertainment predicted delight in corporate websites. In this study, entertainment is the strongest antecedent of delight, highlighting its significance as an essential necessity in increasing a theme park app's probability of delighting users. Hence, theme park app operators and designers can use factors related to the entertainment value of an app to stimulate delight.

Fifth, delight has been found to affect users' continuance intention, recommendation, feedback, and revisit intention, in line with previous research on the behavioral outcomes of delight [3, 6, 8, 32]. Specifically, our findings on the effects of delight on continuance intention suggest that delighted users are likely to retain theme park apps on their smartphones and continue using them. This is particularly important for theme park app operators because many users often delete the app after completing their visit. It is possible to retain users for a theme park app by delighting users 
even though they have completed their visit. In addition, our findings on the positive influences of delight on recommendation and feedback indicate that delighting users is crucial to motivating users' citizenship behaviors. This is consistent with prior findings in [3], which showed that delight positively affects mobile app users' citizenship behaviors, such as word-of-mouth, offering feedback, and helping others to install the apps. Furthermore, delight has been found to predict users' revisit intention regarding theme parks. This confirms the importance of theme park apps as a tool with which to increase revenues for theme parks. A delightful experience with using a theme park app may enable a user to revisit a theme park.

Finally, a significant difference between local and non-local users regarding the relationship between entertainment and delight has been found. The influences of entertainment on delight are stronger for non-local users than local users. This may be because local users are more familiar with the theme park around their residences than non-local users. Therefore, entertainment's role in evoking delight may be weaker for them.

\section{Conclusion}

This study has certain theoretical contributions. First, we introduced delight to examine users' continuance intention and citizenship behaviors in the context of theme park apps. Our findings on the positive effects of delight on continuance intention, recommendation, and feedback indicate the significance of delight, as compared to mere satisfaction in explaining users' behaviors. Second, this study offers new insights by identifying three types of features that can be used to increase the chances of delighting users, including features regarding achievement-related gamification, entertainment, and aesthetic design. Third, our findings on the difference between local and non-local users indicate that we should consider residence type when investigating the determinants of delight in the context of theme park apps.

This study also has some practical implications for theme park app designers and operators. First, our findings on the positive impacts on the part of delight on continuance intention, recommendation, feedback, and revisit intention suggest that app designers and operators should delight their users. Because we found positive impacts on the part of achievement-related gamification, aesthetic design, and entertainment on delight, therefore, the app designers and developers should consider these features when designing and updating a theme park app. For example, theme park operators could offer reward points to visitors when they visit a specific attraction. In addition, because we found a stronger impact on the part of entertainment on delight for non-local users than for local users, app designers and operators should provide differential entertainment for different user groups.

\section{Limitations and future research directions}

This study has certain limitations, which suggest future research directions. First, because we only focused on delight, the significance of satisfaction with theme park apps could also be examined. Future research could compare the importance of both delight and satisfaction in explaining continuance intention, citizenship behaviors, and revisit intention in the context of theme park apps. Second, we limited our consideration of the determinants of delight. Other unexpectedness-related factors could also be included. For instance, further research could examine the role of surprise in predicating delight with theme park apps. Finally, we collected data only in China. Future research could gather data from additional countries to increase the generalizability of our findings.

\section{References}

[1] Tussyadiah, I.P. and D. Wang, Tourists' Attitudes toward Proactive Smartphone Systems. Journal of Travel Research, 2014. 55(4): pp. 493-508.

[2] Kamboj, S. and R. Joshi, Examining the Factors Influencing Smartphone Apps Use at Tourism Destinations: A Utaut Model Perspective. International Journal of Tourism Cities, 2021. 7(1): pp. 135-157.

[3] Hsu, J.S.-C., T.-C. Lin, T.-W. Fu, and Y.-W. Hung, The Effect of Unexpected Features on App Users' Continuance Intention. Electronic Commerce Research and Applications, 2015. 14(6): pp. 418-430.

[4] Oliver, R.L., R.T. Rust, and S. Varki, Customer Delight: Foundations, Findings, and Managerial Insight. Journal of Retailing, 1997. 73(3): pp. 311-336.

[5] Finn, A., Reassessing the Foundations of Customer Delight. Journal of Service Research, 2005. 8(2): pp. 103-116.

[6] Bartl, C., M.H. Gouthier, and M. Lenker, Delighting Consumers Click by Click: Antecedents and Effects of Delight Online. Journal of Service Research, 2013. 16(3): pp. 386-399.

[7] Barnes, D.C. and A. Krallman, Customer Delight: A Review and Agenda for Research. Journal of Marketing Theory and Practice, 2019. 27(2): pp. 174-195.

[8] Barnes, D.C., M.B. Beauchamp, and C. Webster, To Delight, or Not to Delight? This Is the Question Service Firms Must Address. Journal of Marketing Theory and Practice, 2010. 18(3): pp. 275-284. 
[9] Finn, A., Customer Delight: Distinct Construct or Zone of Nonlinear Response to Customer Satisfaction? Journal of Service Research, 2011. 15(1): pp. 99-110.

[10] Ayeh, J.K., N. Au, and R. Law, "Do We Believe in Tripadvisor?" Examining Credibility Perceptions and Online Travelers' Attitude toward Using UserGenerated Content. Journal of Travel Research, 2013. 52(4): pp. 437-452.

[11] Nilashi, M., O. Ibrahim, E. Yadegaridehkordi, S. Samad, E. Akbari, and A. Alizadeh, Travelers Decision Making Using Online Review in Social Network Sites: A Case on Tripadvisor. Journal of Computational Science, 2018. 28: pp. 168-179.

[12] Agusti, D.P.I., Characterizing the Location of Tourist Images in Cities. Differences in User-Generated Images (Instagram), Official Tourist Brochures and Travel Guides. Annals of Tourism Research, 2018. 73: pp. 103-115.

[13] Filieri, R., D.A. Yen, and Q.L. Yu, \#Ilovelondon: An Exploration of the Declaration of Love Towards a Destination on Instagram. Tourism Management, 2021. 85: pp. 21.

[14] Williams, R., Theme Park Fandom: Spatial Transmedia, Materiality and Participatory Cultures. 2020: Amsterdam University Press.

[15] Kirova, V. and T.V. Thanh, Smartphone Use During the Leisure Theme Park Visit Experience: The Role of Contextual Factors. Information \& Management, 2019. 56(5): pp. 742-753.

[16] Omnico. Theme Park Mobile Barometer. 2019 [cited 2021; Available from: https://content.omnicogroup.com/theme-park-mobilebarometer.

[17] Tussyadiah, I.P., The Influence of Innovativeness on on-Site Smartphone Use among American Travelers: Implications for Context-Based Push Marketing. Journal of Travel \& Tourism Marketing, 2016. 33(6): pp. 806-823.

[18] Wang, D., Z. Xiang, and D.R. Fesenmaier, Adapting to the Mobile World: A Model of Smartphone Use. Annals of Tourism Research, 2014. 48: pp. 11-26.

[19] Lamsfus, C., D. Wang, A. Alzua-Sorzabal, and Z. Xiang, Going Mobile: Defining Context for on-the-Go Travelers. Journal of Travel Research, 2014. 54(6): pp. 691-701.

[20] Law, R., I.C.C. Chan, and L. Wang, A Comprehensive Review of Mobile Technology Use in Hospitality and Tourism. Journal of Hospitality Marketing \& Management, 2018. 27(6): pp. 626-648.

[21] Anderson, E.W. and V. Mittal, Strengthening the Satisfaction-Profit Chain. Journal of Service Research, 2000. 3(2): pp. 107-120.

[22] Berman, B., How to Delight Your Customers. California Management Review, 2005. 48(1): pp. 129151.

[23] Esnaashari, S. and M. Rehm, Educational Technology Tools: Longitudinal Views of Students. Proceeding of Twenty-fifth Americas Conference on Information Systems, Cancun, 2019: pp. 1-10.
[24] Xi, N. and J. Hamari, Does Gamification Satisfy Needs? A Study on the Relationship between Gamification Features and Intrinsic Need Satisfaction. International Journal of Information Management, 2019. 46: pp. 210-221.

[25] Koivisto, J. and J. Hamari, The Rise of Motivational Information Systems: A Review of Gamification Research. International Journal of Information Management, 2019. 45: pp. 191-210.

[26] Kirova, V. and T. Vo Thanh, Smartphone Use During the Leisure Theme Park Visit Experience: The Role of Contextual Factors. Information \& Management, 2019. 56(5): pp. 742-753.

[27] Cyr, D., M. Head, and A. Ivanov, Design Aesthetics Leading to M-Loyalty in Mobile Commerce. Information \& Management, 2006. 43(8): pp. 950-963.

[28] Hsieh, S.H., C.T. Lee, and T.H. Tseng, Branded App Atmospherics: Examining the Effect of PleasureArousal-Dominance in Brand Relationship Building. Journal of Retailing and Consumer Services, 2021. 60: pp. 102482.

[29] Dyson, M.P., A.S. Newton, K. Shave, R.M. Featherstone, D. Thomson, A. Wingert, R.M. Fernandes, and L. Hartling, Social Media for the Dissemination of Cochrane Child Health Evidence: Evaluation Study. Journal of Medical Internet Research, 2017. 19(9): pp. 12.

[30] Richard, M.-O., J.-C. Chebat, Z. Yang, and S. Putrevu, A Proposed Model of Online Consumer Behavior: Assessing the Role of Gender. Journal of Business Research, 2010. 63(9-10): pp. 926-934.

[31] Bhattacherjee, A., Understanding Information Systems Continuance: An Expectation-Confirmation Model. MIS Quarterly, 2001. 25(3): pp. 351-370.

[32] Kim, S.S. and J.Y. Son, Out of Dedication or Constraint? A Dual Model of Post-Adoption Phenomena and Its Empirical Test in the Context of Online Services. MIS Quarterly, 2009. 33(1): pp. 49-70.

[33] Torres, E.N. and S. Kline, From Satisfaction to Delight: A Model for the Hotel Industry. International Journal of Contemporary Hospitality Management, 2006. 18(4): pp. 290-301.

[34] Yi, Y. and T. Gong, The Effects of Customer Justice Perception and Affect on Customer Citizenship Behavior and Customer Dysfunctional Behavior. Industrial Marketing Management, 2008. 37(7): pp. 767-783.

[35] Lee, H., S.-B. Yang, and C. Koo, Dyadic Communication in Online Review Platforms: An Exploratory Approach. Current Issues in Tourism, 2021: pp. 1-18.

[36] Merikivi, J., V. Tuunainen, and D. Nguyen, What Makes Continued Mobile Gaming Enjoyable? Computers in Human Behavior, 2017. 68: pp. 411-421.

[37] van der Heijden, H., User Acceptance of Hedonic Information Systems. MIS Quarterly, 2004: pp. 695704.

[38] Griffin, M., B.J. Babin, and D. Modianos, Shopping Values of Russian Consumers: The Impact of 
Habituation in a Developing Economy. Journal of Retailing, 2000. 76(1): pp. 33-52.

[39] Tsang, M.M., S.C. Ho, and T.P. Liang, Consumer Attitudes toward Mobile Advertising: An Empirical Study. International Journal of Electronic Commerce, 2004. 8(3): pp. 65-78.

[40] Hutchinson, J., F. Lai, and Y. Wang, Understanding the Relationships of Quality, Value, Equity, Satisfaction, and Behavioral Intentions among Golf Travelers. Tourism Management, 2009. 30(2): pp. 298-308.

[41] Podsakoff, P.M., S.B. MacKenzie, J.Y. Lee, and N.P. Podsakoff, Common Method Biases in Behavioral Research: A Critical Review of the Literature and Recommended Remedies. Journal of Applied Psychology, 2003. 88(5): pp. 879-903.

[42] Kock, N. and G.S. Lynn, Lateral Collinearity and Misleading Results in Variance-Based Sem: An Illustration and Recommendations. Journal of the Association for Information Systems, 2012. 13(7): pp. 546-580.

[43] Fornell, C. and D.F. Larcker, Structural Equation Models with Unobservable Variables and Measurement Error - Algebra and Statistics. Journal of Marketing Research, 1981. 18(3): pp. 382-388.

[44] Henseler, J., C.M. Ringle, and M. Sarstedt, A New Criterion for Assessing Discriminant Validity in Variance-Based Structural Equation Modeling. Journal of the Academy of Marketing Science, 2015. 43(1): pp. 115-135.

[45] Nitzl, C., J.L. Roldan, and G. Cepeda, Mediation Analysis in Partial Least Squares Path Modeling Helping Researchers Discuss More Sophisticated Models. Industrial Management \& Data Systems, 2016. 116(9): pp. 1849-1864.

[46] Henseler, J., C.M. Ringle, and M. Sarstedt, Testing Measurement Invariance of Composites Using Partial Least Squares. International Marketing Review, 2016. 33(3): pp. 405-431.

[47] Tsang, M.M., S.-C. Ho, and T.-P. Liang, Consumer Attitudes toward Mobile Advertising: An Empirical Study. International Journal of Electronic Commerce, 2004. 8(3): pp. 65-78.

\section{Appendix. Measurement items}

\begin{tabular}{|l|l|l|}
\hline $\begin{array}{l}\text { Constru } \\
\text { ct }\end{array}$ & Measurement items & $\begin{array}{l}\text { Refere } \\
\text { nces }\end{array}$ \\
\hline $\begin{array}{l}\text { Achieve } \\
\text { ment- } \\
\text { related } \\
\text { gamifica } \\
\text { tion }\end{array}$ & $\begin{array}{l}\text { 1. The frequency of interacting with } \\
\text { badges/medals/trophies. } \\
\text { 2. The frequency of interacting with } \\
\text { points/scores/experience points. } \\
\text { 3. The importance of interacting with } \\
\text { badges/medals/trophies. } \\
\text { 4. The importance of interacting with } \\
\text { points/scores/experience points. }\end{array}$ & {$[24]$} \\
\hline $\begin{array}{l}\text { Social- } \\
\text { related } \\
\text { gamifica } \\
\text { tion }\end{array}$ & $\begin{array}{l}\text { 1. The frequency of interacting with } \\
\text { team/cooperation. }\end{array}$ & $\begin{array}{l}\text { 2. The frequency of interacting with } \\
\text { social networking features. } \\
\text { 3. The importance of interacting with } \\
\text { team/cooperation. }\end{array}$ \\
\hline
\end{tabular}

\begin{tabular}{|c|c|c|}
\hline & $\begin{array}{l}\text { 4. The importance of interacting with } \\
\text { social networking features. }\end{array}$ & \\
\hline $\begin{array}{l}\text { Aestheti } \\
\text { c design }\end{array}$ & $\begin{array}{l}\text { 1. The design of theme park app (i.e., } \\
\text { colors, boxes, menus, etc.) is attractive. } \\
\text { 2. The theme park app looks } \\
\text { professionally designed. } \\
\text { 3. The theme park app has good } \\
\text { graphics design. } \\
\text { 4. The theme park app has visually } \\
\text { appealing overall look and feel. } \\
\text { 5. Overall, I find that the theme park } \\
\text { app looks attractive. }\end{array}$ & {$\left[\begin{array}{l}{[36,} \\
37]\end{array}\right.$} \\
\hline $\begin{array}{l}\text { Entertai } \\
\text { nment }\end{array}$ & $\begin{array}{l}\text { 1. I feel that the theme park app is } \\
\text { enjoyable and entertaining. } \\
\text { 2. To me, it is amusing to use the theme } \\
\text { park app. } \\
\text { 3. I feel that it is pleasant to use the } \\
\text { theme park app. } \\
\text { 4. The use of this theme park app gave } \\
\text { me pleasure. }\end{array}$ & $\begin{array}{l}{[38,} \\
47]\end{array}$ \\
\hline Delight & $\begin{array}{l}\text { 1. I felt delighted at some time during } \\
\text { my use of this theme park app. } \\
\text { 2. I felt gleeful at some time during my } \\
\text { use of this theme park app. } \\
\text { 3. I felt elated at some time during my } \\
\text { use of this theme park app. }\end{array}$ & [5] \\
\hline $\begin{array}{l}\text { Continu } \\
\text { ance } \\
\text { intention }\end{array}$ & $\begin{array}{l}\text { 1. I intend to continue using the theme } \\
\text { park app rather than discontinue its use. } \\
\text { 2. My intentions are to continue using } \\
\text { this theme park app than use any } \\
\text { alternative means. } \\
\text { 3. I will recommend others to use the } \\
\text { theme park app.* } \\
\text { 4. If I could, I would like to continue } \\
\text { my use of the theme park app. }\end{array}$ & [31] \\
\hline $\begin{array}{l}\text { Feedbac } \\
\mathrm{k}\end{array}$ & $\begin{array}{l}\text { 1. I will fill out a customer satisfaction } \\
\text { survey regarding the theme park app. } \\
\text { 2. I will provide helpful feedback to the } \\
\text { theme park app service providers. } \\
\text { 3. I will provide information when } \\
\text { surveyed by the theme park app service } \\
\text { providers. } \\
\text { 4. I will inform the theme park app } \\
\text { service providers about issues or } \\
\text { suggestions. }\end{array}$ & [3] \\
\hline $\begin{array}{l}\text { Recomm } \\
\text { endation }\end{array}$ & $\begin{array}{l}\text { 1. I will say positive things about the } \\
\text { theme park app to other people. } \\
\text { 2. I will recommend the theme park app } \\
\text { to anyone who seeks my advice. } \\
\text { 3. I will refer my acquaintances to the } \\
\text { theme park app. }\end{array}$ & [32] \\
\hline $\begin{array}{l}\text { Revisit } \\
\text { intention }\end{array}$ & $\begin{array}{l}\text { 1. I intend to revisit the theme park } \\
\text { again. } \\
\text { 2. It is very likely that I will revisit the } \\
\text { theme park in the future. } \\
\text { 3. The likelihood of my return to the } \\
\text { theme park for another travel is high. }\end{array}$ & [40] \\
\hline
\end{tabular}

